\title{
MITIGATING PROJECTED IMPACTS OF CLIMATE CHANGE AND BUILDING RESILIENCY THROUGH PERMACULTURE: A COMMUNITY 'BEE INSPIRED GARDENS' MOVEMENT IN THE DESERT SOUTHWEST, USA
}

\author{
ROSLYNN BRAIN ${ }^{1}$, JEFFREY ADAMS ${ }^{2}$ \& JEREMY LYNCH ${ }^{3}$ \\ ${ }^{1}$ Utah State University Extension Sustainability, USA \\ ${ }^{2}$ Terrasophia LLC, Utah, USA \\ ${ }^{3}$ In Transition Permaculture, Utah, USA
}

\begin{abstract}
Permaculture, an integrative design process creating resilient and productive landscapes and communities, can serve as a useful mitigation tool for projected climate change impacts. In the United States, the desert southwest town of Moab, Utah, has employed permaculture design in a community initiative called 'Bee Inspired Gardens.' This initiative has harnessed social capital to create resilient landscapes demonstrating pollinator health, water conservation, and perennial food and forage systems. Bee Inspired Gardens have been designed at a University, middle school, charter school, Bureau of Land Management property, hotel, public park, environmental education non-profit, and more. Community members are now harvesting fruit and seeds from existing garden sites, attending educational workshops at the gardens, and volunteering to help with the design and implementation processes. In the desert southwest, climate change projections are for hotter, drier, weather. In preparing for, and working to mitigate, projected impacts, initiatives like 'Bee Inspired Gardens' can serve as models for other communities looking to take positive action in climate mitigation and adaptation.

Keywords: permaculture, climate change, water harvesting, conservation, resiliency, regenerative, pollinator health, perennial food, social structures, desert.
\end{abstract}

\section{INTRODUCTION}

Average temperatures in the United States (US) have risen between 1.3 and 1.9 degrees Fahrenheit since 1895, with the highest rate of increase occurring since 1970 [1]. Substantial scientific research predicts temperatures in most areas of the US will increase another 2 to 4 degrees Fahrenheit over the next few decades [1]. As with many areas globally, the Southwest region of the US is predicted to experience hotter, drier weather due to climate change, yet this region also relies more heavily on irrigation than any other region in the country. Water supplies, primarily driven by winter snow levels in the Sierra Nevada Mountains and the Rocky Mountains, are critical to meeting irrigation needs in the Southwest. In this region, the US Department of Agriculture Southwest Climate Hub [2] has correlated climate change with:

- A prolonged, extreme drought persisting over several years;

- Large, destructive and catastrophic wildfires that have taken both lives and property;

- Expansive areas of forest tree mortality as a result of insect outbreaks;

- A severe decline in reservoir water supplies across the region to previously unseen levels;

- Documented rising temperatures that increase the frequency of heat waves and reduce the frequency of cold snaps. 
Recent regional catastrophes and water shortages have been directly linked to changing climatic conditions in the US Southwest. For example, California experienced its hottest and driest 12-month stretch in 120 years of official record keeping in 2014. Nearly 60 percent of the state endured months of exceptional drought conditions, with the rest in at least moderate drought levels. A lack of water and extreme dryness led to heavy agricultural damage and other direct economic impacts. In 2014 alone, Western drought resulted in \$4 billion in economic losses, and $\$ 1.5$ billion in insured losses [3]. Water is a scarce and vital resource to farmers, ranchers, and the general public in the region. Unfortunately, drought and increased competition for water will be a more frequent reality in coming years [2].

In the face of changing climatic conditions, permaculture can serve as a mitigation and adaptation tool. Permaculture is an integrative framework for designing and creating landscapes and communities that are more resilient and productive (improved recovery time from damage to infrastructure, increased self-reliance, etc.). Resilient and productive landscapes will both mitigate the projected impacts of climate change, and also be more adaptive as climate change impacts temperature and precipitation patterns, alters growing seasons, increases plant moisture stress, and potentially triggers further extreme events. This article shares how permaculture design can serve as a climate change mitigation and adaptation tool, drawing on a specific example of a community movement in the US desert southwest, called "Bee Inspired Gardens."

\section{PERMACULTURE DESIGN AS A SOLUTION}

Permaculture, a merging of the terms "permanent" and "agriculture," was first coined in Tasmania by Bill Mollison and David Holmgren in the mid-1970's. In observing the environmental destruction and social stresses associated with providing basic human needs in an industrial era, Mollison and Holmgren sought a regenerative alternative. This alternative was envisioned as "an integrated, evolving system of perennial or self-perpetuating plant and animal species useful to man" [4]. Holmgren has since expanded the definition to "consciously designed landscapes which mimic the patterns and relationships found in nature, while yielding an abundance of food, fibre and energy for provision of local needs" [5].

Permaculture design is guided by ethics and principles, using a systems lens with feedback loops for adaptation. This holistic framework teaches mimicking the diversity, functionality and resilience of natural ecosystems - a framework that applies beyond landscaping to one's work life, social life, and community. The result is the establishment of land use and settlement systems that are productive, adaptive and resource-efficient in providing abundant and/or diverse yields for meeting human needs, including the need for existing within a healthy and functioning ecosystem. The principles and practices used are drawn from traditional ecological knowledge of indigenous cultures, combined with modern scientific understanding, technological advances, and place-based field experience across many disciplines.

Three ethics guide all permaculture work: "care for the earth", "care for people", and "return and/or share the surplus". These ethics help us reflect on our choices as we work toward the shared goals of individual, societal, and ecosystem well-being. The concept of self-regulation teaches us that our behaviors and choices do matter. Humanity is viewed as an ethical species with a shared responsibility to limit our consumption and to seek forms of production and technology that satisfy our basic needs while providing the highest positive impacts on broader ecological and social systems. The ethics of care for the earth, care for people, and to return and/or share the surplus are operationalized through guiding principles ranging from "long and slow observation" to "creatively using and responding to change." 


\subsection{The permaculture design process}

The permaculture design process - the process applied in the Bee Inspired Gardens initiative, works from patterns to details, cultivating an understanding of the place-based climatic, site, community and socio-economic conditions influencing a project and a vision for what is possible. The design process starts with this assessment and visioning. Assessments include pattern recognition and obtaining baseline information about the climate, regulatory and bio-physical conditions influencing a particular site. Visioning provides the opportunity to actively articulate the desired or ideal future conditions and goals of a project.

Assessment helps us understand where we are, and visioning helps us clarify where we want to go. The creative tension arising from the gap between our current and desired conditions serves as the driver for designing and developing strategies and solutions to move us towards our vision.

A key part of the permaculture design process is assessment and analysis of the conditions one is working with, which begins with observation and research. Climatic information that is important to consider includes the plant hardiness zone, precipitation patterns, length of growing season, depth to frost line, prevailing winds, and other factors. Regulatory information that may be needed includes building codes, setbacks, drainage, water rights, zoning and other ordinances that may influence a particular site or desired function. Biophysical site conditions include topography, aspect, elevation, infrastructure, buildings, access, vegetation, soils, hydrology, wildlife, animals and other site characteristics. The broader climatic, regulatory, and biophysical conditions will help shape the design by providing realistic parameters, allowing you to design effectively from patterns to details, and to fit solutions to place.

As climatic impacts increase, valuing diversity and experimenting with different species and varieties of plants and animals in our landscapes and agriculture will increase in importance. Seeking opportunities to create, enhance and work with microclimates on a given site is important for creating productive systems that are diverse and resilient.

\subsection{Let the design guide the techniques}

A common misunderstanding about permaculture is the belief that specific techniques (such as an organic garden, swale or herb spiral) represent permaculture anywhere that the technique is inserted. While many techniques can be very valuable when included in a permaculture-based design, the technique itself does not represent permaculture until it is placed in the context of the larger site design and development. For example, an herb spiral designed and located to perform multiple functions and form strategic relationships with other elements, techniques and uses of a site within the context of the larger site design is an example of permaculture design. An herb spiral that is undersized, out of place or disconnected from other site uses and features is not. Refraining from the tendency to skip site assessment and immediately apply specific techniques will keep the options open and allow details to be worked out as concepts come together more fully based on observation and interaction.

One way to maximize multi-functional placement of elements is through a zone and sector analysis. This is a technique used to inform the layout and selection of site features and strategies. Zones refer to the spatial layout of different areas of use and management on a site, based upon a site's topography, proximity to living/activity areas, access paths and the timing and energy requirements to manage and harvest. Zones help us use our time and resources wisely, and increase the chances that the systems of a site receive the attention 
needed for proper operations. Sectors are energies moving through or within a particular site. Examples of sectors include sunshine at different times of day and year, wind, run-on or run-off, a favorable or unfavorable view, noise, smells, light pollution, wildlife and wild fire. There may be additional sectors to consider for any given site. Once Sectors are identified, one can explore the strategies to work with the energy from a particular sector. In broad terms, the options available to work with sectors include: blocking, directing, or harvesting.

Taking the sun sector as an example, through multiple elements in passive solar home design, the function of effectively working with the sun sector is performed. A combination of glazing (windows), overhangs, thermal mass, insulation, and ventilation, ensures a passive solar home that harvests sunshine in cool months to warm the building, and blocks sunshine in the hot months to keep the interior space cool. This minimizes the need for additional HVAC systems. The relative location and functional connections of the elements directs sunshine to thermal mass, which absorbs and holds heat to release slowly overtime to maintain a relatively consistent indoor temperature.

Zone and sector analyses inform integrated design for maximized energy efficiency, comfort, and productivity with a resultant decrease in external resources required to meet site needs. A shift from consumption to local production has multiple positive benefits and builds resiliency from supply disruptions and disasters, particularly as many small individual actions achieve scale at the community and watershed level.

\section{BEE INSPIRED GARDENS: A COMMUNITY PERMACULTURE MOVEMENT}

The desert southwest town of Moab, Utah, has been growing a movement that re-envisions how water and resources are used to build resiliency in the wake of climate change. Through prolonged observation and interaction, a collaborative initiative has emerged, resulting in over a dozen permaculture landscapes installed in under two years. One of those sites, Utah State University (USU) Moab, has been a pioneering catalyst of the Bee Inspired Gardens movement and will serve as an example of permaculture principles in action.

\subsection{Background}

In 2013, the USU Moab campus was undergoing a major parking lot upgrade, in which approximately half of the landscaped area would be removed and replanted. The original plan included replacing existing landscaping (planted primarily in juniper shrubs juniperus spp.) with raised flower beds fed by an irrigation drip system. This design did not adequately account for site specific conditions and micro-climate, available on-site resources, nor the opportunity to address or resolve additional site-specific challenges in the process.

After an inquiry to instead redesign the campus landscaping to serve as a teaching tool and an opportunity to foster inspiration both within and outside of the classroom, permission was granted to apply permaculture to the project as a model of climate resiliency. The approval for permaculture design from USU Moab's Dean served as a catalyst for development of a community initiative, called Bee Inspired Gardens.

In light of the new direction intended for campus landscaping, a community visioning meeting was held with USU Extension Sustainability's coordinator and a permaculture intern, a city council representative, owner of a local nursery, director of a local nonprofit building affordable straw bale housing for low-income families, a local communitysupported agriculture provider, US Department of Agriculture Natural Resources Conservation Service's local representative, Moab's Bureau of Land Management representative, director of a nonprofit youth organic gardening organization, permaculture 
designers, and the county bee inspector. During this meeting, representatives discussed community concerns, namely water resources, pollinator population decline, and a lack of community self-sufficiency. In identifying these common concerns, a team was formed that would work to establish educational and interactive spaces throughout the community, under the mission "to inspire efforts toward pollinator health, water conservation, and food and forage systems using gardens, workshops and resources in a way that benefits our community and ecosystems."

\subsection{Human diversity}

The USU Moab garden design process began with slow and thoughtful observation. The USU Extension Sustainability team organized a series of community workshops to teach locals about permaculture while engaging the community actively in the USU Moab garden design process.

The workshop series began with a design charrette and followed by a hands-on work day. Participant observations during the initial workshop were incorporated into the final design of the garden, including an assessment of the need for more parking lot shade (which led to the establishment of shade trees planted in water harvesting tree islands with curb cuts - see Fig. 1) and the need to remediate the recurring issue of freeze and thaw cycles caused by roof downspouts out letting into the parking lot (solved by redirecting water flow into garden green spaces). Within the year, the USU Moab permaculture gardens were installed, showcasing innovative examples of green infrastructure with water harvesting technologies and a perennial food forest with diverse pollinator plantings (Fig. 2).

One of the most important outcomes of the garden was the process that empowered participants to develop their own projects and the model that continues to inspire and engage the community. Highlighted below are several aspects of the project which emphasize the value and impact of permaculture design on the site and community scale.

\subsection{Building a network}

Site analysis and assessment identified existing, underused resources available. Most immediate at USU Moab was the abundance of water runoff available for harvest in the dense urban environment of the site. Impermeable surfaces abounded - as roofs, concrete sidewalks and asphalt parking lots. This included runoff from both on-site surfaces and neighboring buildings. This runoff resource could be harvested by two means: (a) direct conveyance to depressional features in the landscape - called basins or swales; and (b) capture and storage in tanks, or cisterns, to hold the water for use during the dry season and drought periods. The most substantial water harvesting source was the roof of a neighboring hardware store building, which provided an opportunity to form a relationship with the store's management. Excited about the project, the local business offered to finance and install a gutter and downspout system on their building to support water harvesting at the University.

A second community relationship was then developed with a local tree trimming company, who donated woody mulch, a byproduct of their tree trimming work, as a surface layer to increase water retention, contribute to building healthy garden soils, and suppress the growth of undesirable plants. This relationship later led to a partnership in building a pergola for an outdoor social space. Then, a third relationship was formed with a local mule and horse ranch who donated a large quantity of composted animal manures to help amend the soils in the garden. In this case, the ranch's overabundance of resources had become a burden to their operation. Its use in the garden proved a benefit to all parties. 
This process has had a direct benefit in building resilience given climate projections for the Southwest. Permaculture designer Jason Gerhardt calculates over 125,000 gallons of water are now harvested annually at USU Moab either directly into the garden soil or into a series of rain tanks for later use - all in a climate that only gets 9 inches of rain a year. Ultimately, what we observe are localized solutions working in conjunction with available on-site and neighborhood resources, in the form of natural elements and social relationships, that cumulatively demonstrate how to apply these techniques on a larger scale within the city.

\subsection{Techniques used to slow, spread and sink water}

Basins

- Basins are depressional features with capacity for a given amount of water to be retained (temporarily pool) and infiltrated into the surrounding soil. The garden landscape is a sinuous basin and swale system designed to maximize the retention and infiltration potentials of the site. During a precipitation event, water running off the surrounding roofs is directed into the rock lined channel, where it temporarily pools up and soaks into the adjacent soils.

Swales

- Swales can be either on-contour (level) or off-contour (sloped). On-contour swales are used to distribute water evenly across an area. Off-contour swales are used to convey water slowly between points, allowing for infiltration to occur along the way. USU Moab's swales were designed off-contour, with an approximate $1 \%$ to $2 \%$ slope to direct water into basins and intentional overflow areas.

Curb cuts

- Curb cuts are strategically located openings in a curb and gutter system or sidewalk that allows the flow of storm water to enter a depressional landscaped area. Curb cuts are often located in series along a parking lot or roadway, providing redundancy and increased capacity as one curb cut fed basin fills the water flows down to the next. Curb cuts were included in two parking lot vegetation islands at USU Moab, shown in Fig. 1. A simple shift from having these vegetation islands be raised, as is currently the norm, to being depressional allows for hundreds of gallons of water to be retained and absorbed during rain events, providing abundant, deep infiltration of water to support the plantings. Shade trees planted in these basins are growing large and fast, providing valuable shade to lower the heat islands of this parking area, making for a more inviting and healthy space, even in the middle of a sea of asphalt.

Cisterns or tanks

- Storage containers of various sizes can be used to hold water during precipitation events for use at later times. The volume of water stored can be matched to the available roof area and precipitation patterns, and should always include an overflow to an appropriate location. 


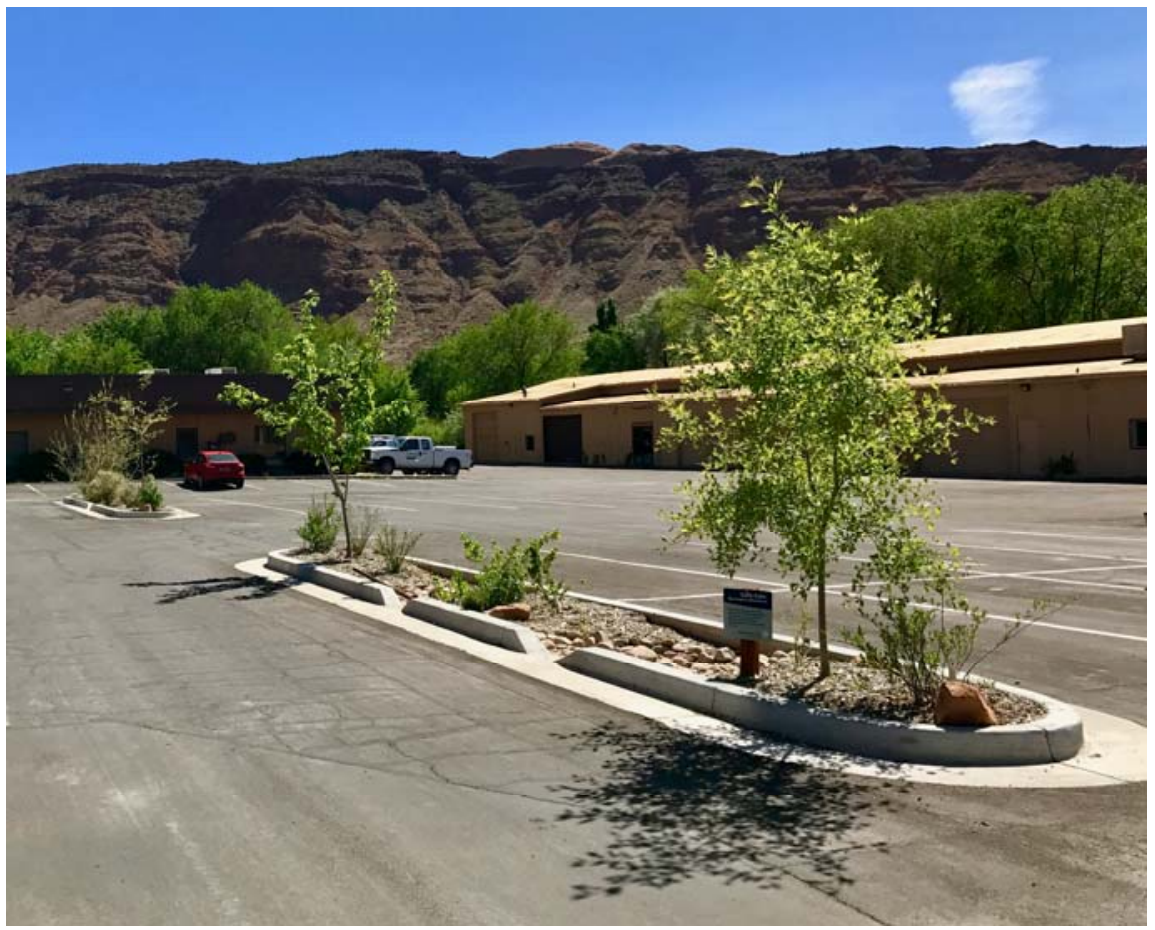

Figure 1: Parking lot shade islands with curb cuts and basins, USU Moab. (Photo credit: Roslynn Brain.)

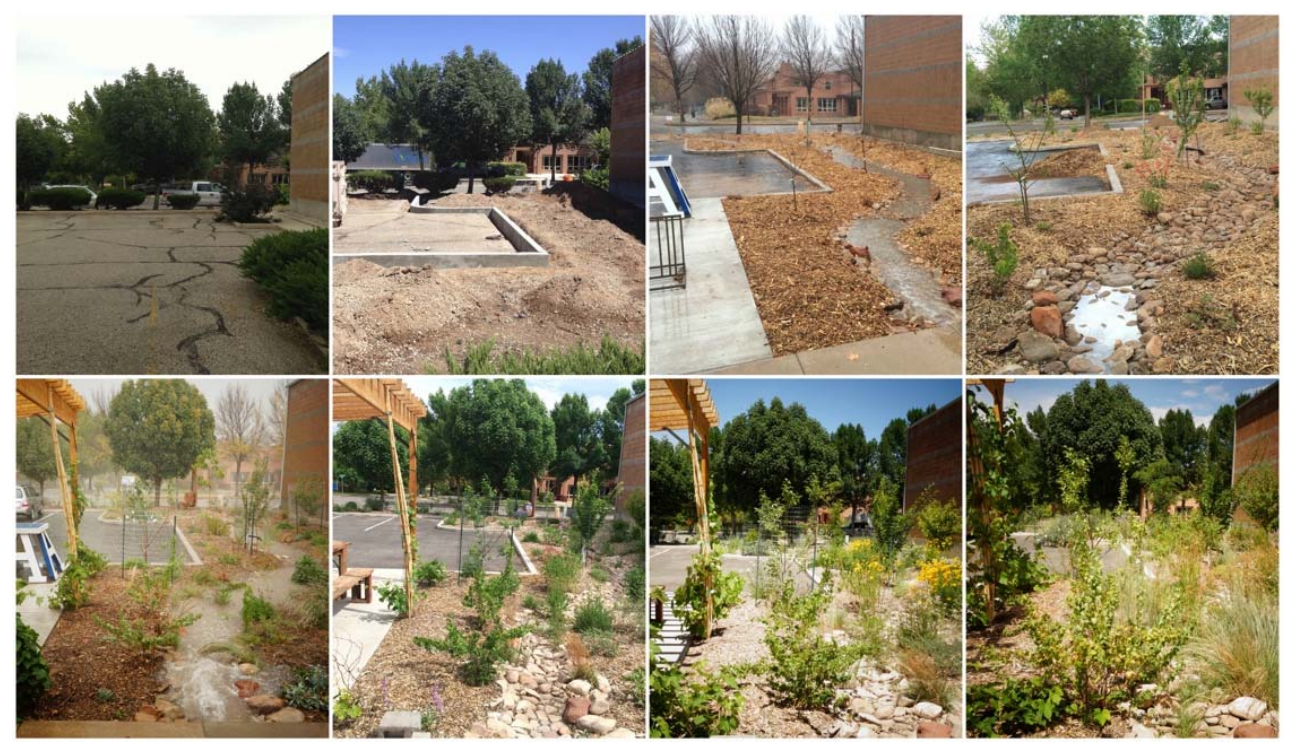

Figure 2: USU Moab Garden Progression over two years. (Photo credit: Roslynn Brain.) 
Supplemental drip

- Most plants in an arid climate like Moab require some level of supplemental irrigation during their establishment period and occasionally during periods of extreme or prolonged drought. Plant establishment typically requires 1 or 2 growing seasons for plant roots to become robust and able to more effectively survive on available soil moisture from local precipitation and water harvesting strategies. Supplemental irrigation can be provided by hand watering, drip irrigation or a combination. Providing infrequent, deep watering is more effective at promoting deep root growth and plant establishment than frequent, shallow watering. USU Moab's permaculture gardens were established primarily via hand watering (through an integrated design of the rainwater cisterns and garden basins in which a series of pipes direct stored rainwater to flood into the rock-lined garden swales). Only beds surrounding the buildings use drip irrigation, as the irrigation systems were already installed and building overhangs limit direct precipitation.

\subsection{Carbon sequestration}

Carbon sequestration comes in the form of planting with diverse, perennial trees, shrubs, and plants, and using organic mulches, as well as building soil structure. According to Colorado State University Extension [6], wood or bark chip mulch is ideal around trees, shrubs, perennials, and small fruits. A wood/bark chip mulch creates a favorable environment for earthworms and soil microorganisms, which helps to reduce soil compaction in time. In perennial and shrub beds, wood/bark chips can reduce the need for irrigation by as much as $50 \%$ [6]. Also, when used on the soil surface as mulch, wood/bark chips do not tie-up soil nitrogen. USU Moab's permaculture gardens used approximately six inches of wood mulch during installation with a fresh layer added annually or as needed to maintain cover. Listed benefits of wood mulch by Colorado State University Extension [6] include:

- $\quad$ Reduces evaporation from soil surface, cutting water use by $25-50 \%$;

- Organic mulches promote soil microorganism activity, which in turn, improves soil tilth and helps lessen soil compaction;

- Stabilizes soil moisture;

- Controls weeds, which rob soil moisture;

- Moderates soil temperature extremes;

- Controls erosion;

- Gives a finished look, improving aesthetic quality.

Where does carbon sequestration tie in with wood mulch? Although a complicated relationship, research published in Nature [7], by scientists from the University of Texas at Austin, the Smithsonian Tropical Research Institute, and Boston University assessed the carbon and nitrogen cycles under different mycorrhizal (fungus and root relationships) regimens including those in wood mulch and found that plants linked with fruiting, or mushroom-type, fungi stored $70 \%$ more carbon per unit of nitrogen in soil. The fungi uptake of organic nitrogen on behalf of the plant was found to out-compete soil microorganisms that decompose organic matter and release carbon [7].

In addition to the carbon sequestration occurring through maturing perennial plants and wood mulch, carbon emissions have also been reduced through the maintenance required by 
the design. As opposed to mono-planted lawns or landscapes, the USU Moab gardens do not require any fossil-fuel equipment to maintain.

\subsection{Plant selection and placement}

An important component of the garden design at USU Moab was an effort to take into account local and regional natural and human history. Permaculture stresses the value of ancestral and indigenous values in contemporary design and how these aspects contribute to the transmission of cultural wisdom. In developing a plant palette for the USU Moab permaculture gardens, the history of land use and settlement in the Moab Valley was taken into consideration. The plant palettes drew from distinctive epochs in regional history, including: native plants harvested and used by early indigenous inhabitants of the valley (e.g. Indian Rice Grass, Achnatherum hymenoides, and Sumac, Rhus integrifolia), perennial crops (stone fruit trees) grown by later Mormon settlers and a plethora of herbal, medicinal and edible plants propagated for use in contemporary times.

The planting pattern was designed around the permaculture concept of guilds, which - in gardens, are groups of plants chosen for their mutually beneficial and interacting functions, planted in proximity to one another. The layout mimics the Seven-Layer Forest Garden design described in Toby Hemenway's book Gaia's Garden [8], wherein the layering of a natural forest ecosystem includes a root layer, groundcover and grasses, herbaceous perennials, a shrub understory, low and high-tree canopies and vines. Each plant at USU was chosen to fill a particular niche or function in this system of layers, and each was placed so to interact with the species planted in proximity to it.

One example of a plant guild in the USU Moab permaculture garden is the Santa Rosa Plum (Prunus salicina) guild, which includes: Nanking Cherry (Prunus tomentosa), Common Yarrow (Achillea millefolium), Beardtongue Penstemon (Penstemon Palmeri) and Thyme (Thymus vulgaris). In this guild, each plant serves as a unique pollinator attractant. In addition, the thyme grows low and sprawling as a groundcover, the yarrow draws deep roots to break up compacted soils and contributes surface mulch through seasonal leaf-drop, the penstemon provides an early season bloom for pollinators and non-competitive drought tolerant characteristics, the Nanking cherry offers bird and beneficial insect habitat as well as shade from summer sun, and a break from seasonal winds, and the plum tree provides additional shade (creating a microclimate for other species) as well as food production for people. The thyme has culinary uses, the yarrow is dried for medicinal uses, and the Nanking cherry provides an early season berry for birds and people. These are just a few of the interacting and overlapping functions which formed the basis for the plant palette, and it is just one of several plant guilds designed for the permaculture garden, harboring native and adapted species such as Banana Yucca (Yucca baccata), Grapevines (Vitus labrusca), Jujube Tree (Ziziphus jujuba), Apache Plume (Fallugia paradoxa) and Golden Currant (Ribes aureum).

Throughout the design process, emphasis was put on designing for place. This entailed designing for regional climate (present and future), local context (neighborhood and site specific), and culture (demographics and site management) in an integrative way that seeks to unite what are typically viewed as disparate elements.

\subsection{Other Bee Inspired Garden sites}

Although aspects of the design vary between garden sites throughout the town of Moab Utah, the key elements of pollinator health, water conservation, and perennial food and forage systems remain the same. Sites range from a remote desert site on a reclaimed cattle range to 
a rainwater-fed pollinator garden at a K- $6^{\text {th }}$ grade charter school. Consistent elements in all garden designs, implementation, and maintenance include involving community members, creating educational workshops, including interpretive signage, providing feedback when input is sought, and sharing the abundance provided.

\section{ADOPTING THESE PRACTICES IN YOUR COMMUNITY}

Designing landscapes, buildings and communities through the ethics and principles of permaculture is a way to build resiliency in the wake of the challenges of global climate change. Permaculture design can also support the shift from our current economic growth model dependent on machines and extractive industries with high greenhouse gas emissions to one focused on resilience and the integrated health of human communities and broader ecological systems. In addition to the main ethics and principles of permaculture, the following is recommended if you are interested in adopting these practices in your community:

- Educate yourself about permaculture. Take a permaculture design certification course through a credible organization, ideally based in your geographic region.

- Spend time observing and interacting with your community (key stakeholders, change agents, social networks). Inventory your own skills and resources and those within the community. Vision the ideal future conditions for your site and community. Use this information to decide where to best direct your energy and resources.

- Establish a collaborative team and start to implement small projects; use this as a trial ground to test ideas and garner feedback on how to improve. Use these demonstrations as leverage points to help city government, schools and others see how the design process works.

- As a resource starting point, read Toby Hemenway's Gaia's Garden and The Permaculture City, Gary Nabhan's Growing Food in a Hotter Drier Land, and Brad Lancaster's Rainwater Harvesting for Drylands and Beyond Volumes 1 and 2. As well, it is recommended to seek out the indigenous knowledge of native plant communities from your area - through research and direct conversation.

\section{ACKNOWLEDGEMENTS}

The authors would like to thank all members of the Bee Inspired Garden team, USU Moab permaculture garden designer Jason Gerhardt and the community of Moab for their vision, involvement, and support.

\section{REFERENCES}

[1] Melillo, J.M., Richmond, T.C. \& Yohe, G.W., Highlights of climate change impacts in the United States: The third national climate assessment. US Global Change Research Program, 148 pp., 2014.

[2] USDA Southwest Climate Hub, Southwest region fact sheet, Online. http://swclimatehub.info/sw-region-fact-sheet, 2014.

[3] Aon Benfield. 2014 Annual global climate and catastrophe report: Impact reporting. Online. http://thoughtleadership.aonbenfield.com/Documents/20150113 ab_if_annual_climate_catastrophe_report.pdf, 2014.

[4] Mollison, B. \& Holmgren, D., Permaculture One: A Perennial Agriculture for Human Settlements, Tagari Publications, 1978. 
[5] Holmgren, D., Permaculture: Principles and Pathways Beyond Sustainability. Holmgren Design Services, 2002.

[6] Colorado State University Extension, Mulching with wood/bark chips, grass clippings, and rock, Colorado Master Gardener Garden Notes, Online. http://www.ext.colostate.edu/mg/Gardennotes/245.html, 2015.

[7] Averill, C., Turner, B. \& Finzi, A., Mycorrhiza-mediated competition between plants and decomposers drives soil carbon storage. Nature: International Weekly Journal of Science. Online. http://www.nature.com/nature/journal/v505/n7484/full/ nature12901.html, 2014.

[8] Hemenway, T., Gaia's Garden, Chelsea Green Publishing, 2009. 